Author Manuscript Published OnlineFirst on October 21, 2015; DOI: 10.1158/2159-8290.CD-14-0673

Author manuscripts have been peer reviewed and accepted for publication but have not yet been edited.

Targeting the ribosome to treat MYC-driven lymphoma

\title{
Combination therapy targeting ribosome biogenesis and mRNA translation synergistically extends survival in MYC-driven lymphoma.
}

Jennifer R. Devlin ${ }^{1}$, Katherine M. Hannan ${ }^{1,2}$, Nadine Hein ${ }^{1,2}$, Carleen Cullinane ${ }^{1,3}$, Eric Kusnadi ${ }^{1,3}$, Pui Yee $\mathrm{Ng}^{1}$, Amee J. George ${ }^{1,2,4}$, Jake Shortt ${ }^{1,3}$, Megan J. Bywater ${ }^{1, \#}$, Gretchen Poortinga ${ }^{1,5}$, Elaine Sanij ${ }^{1,6}$, Jian Kang ${ }^{1}$, Denis Drygin $^{7}$, Sean O’Brien ${ }^{8}$, Ricky W. Johnstone ${ }^{1,3,6}$, Grant A. McArthur ${ }^{1,3,5}$, Ross

D. Hannan ${ }^{1,2,3,4,9,10,11^{*}}$ and Richard B. Pearson ${ }^{1,3,9,10,11 \text { * }}$

${ }^{1}$ Division of Research, Peter MacCallum Cancer Centre, East Melbourne, 3002, VIC, Australia;

${ }^{2}$ John Curtin School of Medical Research, Australian National University, Acton, 2601, ACT, Australia;

${ }^{3}$ Sir Peter MacCallum Department of Oncology, University of Melbourne, Parkville, 3052, VIC, Australia;

${ }^{4}$ School of Biomedical Sciences, University of Queensland, St Lucia, 4072, QLD, Australia;

${ }^{5}$ Department of Medicine, St Vincent's Hospital, University of Melbourne, Fitzroy, 3065, VIC, Australia;

${ }_{7}^{6}$ Department of Pathology, University of Melbourne, Parkville, 3052, VIC, Australia;

${ }^{7}$ Pimera Inc, San Diego, CA, USA;

${ }^{8}$ Senhwa Biosciences, San Diego, CA, USA;

${ }^{9}$ Department of Biochemistry and Molecular Biology, University of Melbourne, Parkville, 3052, VIC, Australia;

${ }^{10}$ Department of Biochemistry and Molecular Biology, Monash University, Clayton, 3168, VIC, Australia;

${ }^{11}$ These authors contributed equally to this work;

${ }^{*}$ Corresponding authors

\# Current affiliation: Department of Biochemistry, University of Cambridge, Cambridge, UK

RUNNING TITLE: Targeting the ribosome to treat MYC driven lymphoma

KEYWORDS: Ribosome biogenesis; mRNA translation; protein synthesis; PI3K/AKT/mTOR signaling; RNA polymerase I inhibition; combination therapy

ABBREVIATIONS: Phosphatidylinositol-3 kinase (PI3K); mammalian target of rapamycin (mTOR); mammalian target of rapamycin complex 1 (mTORC1); eukaryotic initiation factor 4E (elF4E); Bcl-2 modifying factor (BMF); ribosomal 
Author Manuscript Published OnlineFirst on October 21, 2015; DOI: 10.1158/2159-8290.CD-14-0673

Author manuscripts have been peer reviewed and accepted for publication but have not yet been edited.

Targeting the ribosome to treat MYC-driven lymphoma

protein (RP); ribosomal DNA (rDNA); ribosomal RNA (rRNA); RNA polymerase I (Pol I); internal ribosome entry site (IRES); combination drug index (CDI); untranslated region (UTR); 5'terminal oligopyrimidine (TOP); quantitative real-time polymerase chain reaction (qRT-PCR); bromodomain and extra-terminal (BET); immunoprecipitation (IP); elF4E binding protein 1 (4EBP1); mouse double minute 2 homolog (MDM2); Australia New Zealand Clinical Trials Registry Number (ACTRN)

FINANCIAL SUPPORT: This work was supported by the National Health and Medical Research Council (NHMRC) of Australia project grants (\#1043884, 251608, 566702, 166908, 251688, 509087, 400116, 400120, 566876) and a NHMRC Program Grant (\#1053792). Researchers were funded by NHMRC Fellowships (R.W.J, G.A.M. R.D.H, R.B.P), Cancer Council of Victoria Sir Edward Weary Dunlop Fellowship (G.A.M), Lorenzo and Pamela Galli Charitable Trust (G.A.M) and the Leukaemia Foundation of Australia (PhD scholarship to J.R.D).

\section{CORRESPONDENCE FOOTNOTE}

Corresponding Authors: Richard B. Pearson, Oncogenic Signaling and Growth Control Program, Peter MacCallum Cancer Centre, Locked Bag 1, A'Beckett Street, Melbourne, Victoria 8006, Australia. Email: rick.pearson@petermac.org Phone: (61) 39656 1247, Fax: (61) 39656 3738;

Ross D. Hannan, John Curtin School of Medical Research, Australian National University College of Medicine, Biology and Environment, Building 131, Garran Road, Acton, Australian Capital Territory 2601, Australia. Email : ross.hannan@anu.edu.au Phone : (61) 261256312 
Author Manuscript Published OnlineFirst on October 21, 2015; DOI: 10.1158/2159-8290.CD-14-0673

Author manuscripts have been peer reviewed and accepted for publication but have not yet been edited.

Targeting the ribosome to treat MYC-driven lymphoma

\section{CONFLICTS OF INTEREST}

D. Drygin is VP (R\&D) of Pimera Inc., San Diego, CA, USA. S. O'Brien is VP (Corporate Development) of Senhwa Biosciences, Inc., San Diego, CA, USA.

R.D. Hannan is Chief Scientific Advisor to Pimera Inc. R. W. Johnstone has a commercial research grant and has received honoraria for service on the speakers' bureau for Novartis. G. A. McArthur has commercial research grants from Celgene and Pfizer. No potential conflicts of interest were disclosed by the other authors.

\section{ABSTRACT}

Ribosome biogenesis and protein synthesis are dysregulated in many cancers, with those driven by the proto-oncogene $c-M y c$ characterized by elevated Pol I-mediated ribosomal rDNA transcription and mTORC1/elF4E-driven mRNA translation. Here we demonstrate that coordinated targeting of rDNA transcription and $\mathrm{PI} 3 \mathrm{~K} / \mathrm{AKT} / \mathrm{mTORC} 1-d e p e n d e n t$ ribosome biogenesis and protein synthesis provides a remarkable improvement in survival in MYCdriven B-lymphoma. Combining an inhibitor of rDNA transcription (CX-5461) with the mTORC1 inhibitor everolimus more than doubled survival of E $\mu-M y c$ lymphoma-bearing mice. The ability of each agent to trigger tumor cell death via independent pathways was central to their synergistic efficacy. CX-5461 induced nucleolar stress and p53 pathway activation, while everolimus induced expression of the pro-apoptotic protein BMF that was independent of p53 and reduced expression of RPL11 and RPL5. Thus targeting the network controlling the synthesis and function of ribosomes at multiple points provides a potential new strategy to treat MYC-driven malignancies. 
Author Manuscript Published OnlineFirst on October 21, 2015; DOI: 10.1158/2159-8290.CD-14-0673

Author manuscripts have been peer reviewed and accepted for publication but have not yet been edited.

Targeting the ribosome to treat MYC-driven lymphoma

STATEMENT OF SIGNFICANCE: Treatment options for the high proportion of cancers driven by MYC are limited. We demonstrate that combining pharmacological targeting of ribosome biogenesis and mTORC1-dependent translation provides a remarkable therapeutic benefit to $\mathrm{E} \mu$-Myc lymphomabearing mice. These results establish a rationale for targeting ribosome biogenesis and function to treat MYC-driven cancer.

\section{INTRODUCTION}

The abnormal expression and activity of the proto-oncogene $c-M y c$, a key regulator of cell growth, proliferation and survival, occurs in greater than $30 \%$ of cancers including a high proportion of hematologic malignancies and solid tumors such as ovarian, prostate, HER2/ER/PR-negative breast cancer and melanoma (1-6). The transcription factor c-MYC functions as a global controller of protein biosynthesis, with the regulation of components of the ribosome biogenesis machinery being one of the most consistent gene expression signatures associated with MYC activation $(7,8)$. MYC transcriptional targets are important for key steps in the ribosome biogenesis process including the synthesis of ribosomal RNAs (rRNA) and proteins (RPs) as well as the expression of specific translation initiation factors (e.g. eukaryotic initiation factor 4E (elF4E)) $(2,9-11)$. In particular, the robust upregulation of genes encoding all members of the RNA polymerase I (Pol I) complex, which is responsible for transcription of the $47 \mathrm{~S}$ pre-rRNA encoding genes ( $r D N A)$, is a key component of MYC's gene expression signature $(9,10$, 12, 13). Importantly, we recently demonstrated that rDNA transcription, a key rate-limiting step for ribosome biogenesis, is specifically targeted by the novel small molecule inhibitor CX-5461, which is currently in Phase I trial (14). CX- 
Author Manuscript Published OnlineFirst on October 21, 2015; DOI: 10.1158/2159-8290.CD-14-0673

Author manuscripts have been peer reviewed and accepted for publication but have not yet been edited.

Targeting the ribosome to treat MYC-driven lymphoma

5461 exhibits potent and selective single-agent therapeutic efficacy against MYC-driven B-lymphoma cells in vivo (12). The efficacy of this agent was mediated through induction of a nucleolar stress response characterized by the activation of p53-mediated apoptosis following binding and sequestration of the ubiquitin ligase MDM2 by RPL11 and RPL5 (12) (reviewed in 13, 15-17).

Elevated rates of protein synthesis are also essential for MYC-driven lymphomagenesis with the up-regulation of mammalian target of rapamycin complex 1 (mTORC1)/elF4E-dependent protein translation demonstrated to sensitize MYC-driven malignancies to mTOR inhibition $(18,19)$. The $\mathrm{PI} 3 \mathrm{~K} / \mathrm{AKT} / \mathrm{mTOR}$ and RAS pathways cooperate with MYC to control ribosome biogenesis and protein synthesis in normal and malignant cells $(20,21)$, with the $\mathrm{PI3K} / \mathrm{AKT} / \mathrm{mTOR}$ pathway in particular regulating ribosome biogenesis and function at multiple steps. PI3K/AKT/mTOR signaling controls rRNA synthesis at the levels of rDNA transcription and rRNA processing as well as RP synthesis by regulating translation initiation for 5 ' terminal oligopyrimidine (TOP) containing mRNAs $(20,22-24)$. PI3K/AKT/mTOR signaling modulates mRNA translation at both the initiation and elongation stages including the promotion of elF4E-dependent 5'CAP-dependent translation initiation $(20,21$, $23,25,26)$. We and others have previously demonstrated the vulnerability of MYC-driven B-lymphoma cells to a number of targeted therapeutic strategies that inhibit PI3K/AKT/mTOR signaling $(18,20,27-31)$. However in all cases disease relapse occurred despite continuing single agent therapy.

It is becoming increasingly apparent that the maximum inhibition of entire signaling networks is a paradigm for improved anti-tumor response $(32,33)$. A 
Author Manuscript Published OnlineFirst on October 21, 2015; DOI: 10.1158/2159-8290.CD-14-0673

Author manuscripts have been peer reviewed and accepted for publication but have not yet been edited.

Targeting the ribosome to treat MYC-driven lymphoma

common mechanism through which cancer cells acquire resistance is to bypass the signaling module that is targeted by a particular therapy. By targeting signaling and transcriptional networks at multiple nodes the development of resistance may be delayed and potentially even prevented (33). Despite the success of strategies targeting the biogenesis and function of the protein synthetic machinery at the levels of rDNA gene transcription (12, 14, 27), RP synthesis (30) and mTORC1-dependent mRNA translation (18) in isolation, it is clear that optimal treatment of MYC-driven malignancies will require the potency of therapeutic strategies that target the ribosome to be maximized. We hypothesized that multi-point inhibition of the ribosome network via coordinated targeting of the PI3K/AKT/mTOR signaling pathway and rDNA transcription would improve therapeutic outcomes in cancers driven by dysregulated MYC expression and activity. In this work we identify the combined inhibition of ribosome biogenesis and function with selected small molecule inhibitors targeting multiple points as a novel and highly potent strategy to treat MYC-driven B-cell lymphoma.

\section{RESULTS}

\section{Inhibitors of PI3K/AKT/mTOR signaling suppress rDNA transcription} independent of nucleolar-stress mediated p53 activation

Apoptosis and cell cycle arrest in response to the disruption of ribosome biogenesis triggered by knockdown of RPs or inhibition of rDNA transcription have been causally linked to induction of the nucleolar stress response (12, $14,34,35)$. Activation of the tumor suppressor protein $p 53$, mediated via the binding of a 5 S rRNA-RPL11-RPL5 complex to the E3-ubiquitin-ligase MDM2 
Author Manuscript Published OnlineFirst on October 21, 2015; DOI: 10.1158/2159-8290.CD-14-0673

Author manuscripts have been peer reviewed and accepted for publication but have not yet been edited.

Targeting the ribosome to treat MYC-driven lymphoma

is a key feature of this stress response $(9,15-17,36,37)$. To evaluate whether PI3K/AKT/mTOR pathway inhibition induced apoptosis (29) via a nucleolar stress mechanism in response to disruption of ribosome biogenesis, we treated $T p 53^{W T} \mathrm{E} \mu-M y c$ B-lymphoma cells in culture with a range of PI3K/AKT/mTOR inhibitors (Fig.1; AKTi-1/2 (AKT), KU-63794 (pan-mTOR), BEZ-235 (PI3K/mTOR) and everolimus (mTORC1)). Measurement of the abundance of the $47 \mathrm{~S} 5$ 'external transcribed spacer sequence (ETS) was performed to evaluate the effect of inhibitors on rDNA transcription initiation rates that we have shown to reflect changes in newly synthesized $47 \mathrm{~S}$ rRNA levels in E $\mu-M y c$ B-lymphoma cells in response to CX-5461 treatment and inhibition of AKT and mTORC1 $(12,20)$. Importantly, measurement of 5'ETS levels allows evaluation of changes to the initiation of rRNA synthesis in vivo $(12,27)$.

Despite the robust suppression of rDNA transcription initiation rates (Fig.1A), the induction of E $\mu-M y c$ B-lymphoma cell apoptosis achieved by multiple inhibitors of PI3K/AKT/mTOR pathway signaling (Fig.S1A) was not associated with p53 activation, as demonstrated by the absence of p53 protein accumulation (Fig.1B) or p53 target gene (p21, puma) up-regulation (Fig.S1B). This was despite potent inhibition of phosphorylation of key substrates of AKT (PRAS40) and mTORC1 (RPS6 and 4EBP1) signaling (Fig. S1C). In direct contrast to signaling inhibitors and consistent with previous results $(12,14)$, inhibition of rDNA transcription by the novel Pol I transcription inhibitor, CX5461, was association with a robust accumulation of p53 protein (Fig.1B) and increased p53 target gene expression (Fig.S1B). The effects of AKTi-1/2 and everolimus with respect to nucleolar morphology (assessed by localization of 
Author Manuscript Published OnlineFirst on October 21, 2015; DOI: 10.1158/2159-8290.CD-14-0673

Author manuscripts have been peer reviewed and accepted for publication but have not yet been edited.

Targeting the ribosome to treat MYC-driven lymphoma

the nucleolar protein Fibrillarin) were compared to those of CX-5461. While CX-5461 resulted in the dispersal of Fibrillarin and the loss of multiple nucleoli, AKTi-1/2 and everolimus had no effect on nucleolar morphology of $\mathrm{E} \mu-M y c$ lymphoma cells (Fig.1C).

It is thought that the increased availability of free (i.e. non-ribosome incorporated) RPs, specifically RPL11 and RPL5, is essential for the nucleolar stress response upon disruption of ribosome biogenesis. Free RPL11 and RPL5 are able to bind in an inhibitory manner to the p53 ubiquitin ligase MDM2, resulting in p53 accumulation $(16,17,36)$. However, while CX-5461 treatment robustly increased the binding of critical RPs (RPL11 and RPL5) to MDM2, as expected from previous studies (12), AKTi-1/2 treatment had no effect on RP binding to MDM2 compared to control (Fig.1D and S1D). To examine the ability of targeted inhibitors to modulate RP abundance, free RP populations were isolated from $\mathrm{E} \mu-M y c$ lymphoma cells treated with AKTi-1/2 or CX-5461. Interestingly assessment of free versus total RP populations revealed that AKTi-1/2 significantly decreased the abundance of free RPL11, as well as a modest decrease in free RPL5 (Fig.1E). In contrast, CX-5461 robustly increased the abundance of both free RPs (Fig.1E). Thus the reduced expression of RPL11 and RPL5, critical mediators of the nucleolar stress response, is likely to be responsible for the absence of nucleolar stress-dependent p53 pathway activation following inhibition of AKT/mTORC1 signaling, despite the robust inhibition of rDNA gene transcription. The reduced abundance of free RPs was not associated with changes in Rp/11 or Rp/5 mRNA levels (Fig.S1E) indicating that AKTi-1/2 treatment did not alter transcription of genes encoding the RPs. Instead decreased RPL11 and RPL5 
Author Manuscript Published OnlineFirst on October 21, 2015; DOI: 10.1158/2159-8290.CD-14-0673

Author manuscripts have been peer reviewed and accepted for publication but have not yet been edited.

Targeting the ribosome to treat MYC-driven lymphoma

protein abundance was associated with altered mRNA translation profiles of E $\mu-M y c$ B-lymphoma cells. Specifically there was a significant decrease $(24.9$ $+/-0.8$ percent) in the ratio of the actively translating polysomes to the subpolysomes (comprising the $40 \mathrm{~S}, 60 \mathrm{~S}$ and $80 \mathrm{~S}$ monomer peaks) following AKTi-1/2 treatment (Fig.1F). Thus AKTi-1/2 treatment mediated changes in ribosomal activity in E $\mu-M y c$ lymphoma cells resulting in decreased abundance of free RPs. The absence of any effects on either the transcription of RP-encoding genes (Fig.S1E; Rp/11 and Rp/5) or the polysome profile following CX-5461 treatment (Fig.1F) suggests that the accumulation of free RPL11 and RPL5 induced by treatment with CX-5461 results from continued RP synthesis despite suppression of rDNA transcription and ribosome biogenesis.

\section{PI3K/AKT/mTOR inhibitor- but not CX-5461-mediated B-lymphoma apoptosis is associated with induction of pro-apoptotic BMF protein.}

In the absence of p53 pathway activation, the inhibitors of PI3K/AKT/mTOR signaling must induce $\mathrm{E} \mu-\mathrm{Myc}$ B-lymphoma cell apoptosis via alternative mechanism(s). Inhibition of PI3K/AKT/mTOR signaling is reported to drive the transient up-regulation of the translation of specific mRNAs containing regulatory internal ribosome entry site (IRES) elements in the 5'untranslated region (UTR) (38), including the pro-apoptotic $\mathrm{BH}$-only protein $\mathrm{Bcl}-2$ modifying factor (BMF) $(29,39)$. In response to AKTi-1/2, KU-63794, BEZ-235 and everolimus treatment a robust increase in BMF protein abundance was detected in E $\mu-M y c$ lymphoma cells (Fig.1G), while CX-5461 treatment had no effect. These findings implicate BMF in B-lymphoma cell apoptosis induced by our panel of PI3K/AKT/mTOR inhibitors, while CX-5461 induces p53- 
Author Manuscript Published OnlineFirst on October 21, 2015; DOI: 10.1158/2159-8290.CD-14-0673

Author manuscripts have been peer reviewed and accepted for publication but have not yet been edited.

Targeting the ribosome to treat MYC-driven lymphoma

mediated-apoptosis independent of increased BMF expression. In support of this hypothesis, the absence of BMF protein expression $\left(\mathrm{Bmf}^{/-} \mathrm{E} \mu-\mathrm{Myc} \mathrm{B}-\right.$ lymphoma cells - Fig.S1F) did not alter the sensitivity of B-lymphoma cells to CX-5461 induced apoptosis (Fig.S1G). In contrast, in comparison to Blymphoma cells wild-type for Bmf, the absence of BMF protein significantly ablated the increase in apoptosis induced by AKTi-1/2 (Fig.S1H).

\section{Combined inhibition of mTORC1 signaling and rDNA transcription cooperates to treat MYC-driven B-cell lymphoma in vivo}

The ability of PI3K/AKT/mTOR inhibitors and CX-5461 to induce B-lymphoma cell apoptosis via independent pathways led us to hypothesize that coordinated targeting of ribosome biogenesis and protein synthesis would improve outcomes in MYC-driven B-lymphoma. To test this hypothesis in vivo, C57BI/6 mice with transplanted E $\mu-M y c$ B-lymphoma were treated with everolimus, the most clinically advanced PI3K/AKT/mTOR pathway inhibitor in our panel, in combination with CX-5461. In mice transplanted with two different Tp53 wild-type $\left(T p 53^{\mathrm{WT}}\right)$ E $\mu-M y c$ clones, co-treatment with everolimus and CX-5461 resulted in a robust survival benefit compared to either single agent therapy (Fig.2A-B). In both experiments the length of the survival extension provided by combination therapy was more than double that achieved with CX-5461 alone (Fig.2A: 50.0 +/- 5.6 (combination) vs. 20.7 +/- 1.9 (CX-5461) and Fig.2B: 36.2 +/- 4.2 (combination) vs. 15.1 +/- 1.9 (CX5461) days survival beyond control group). Thus strong cooperation between everolimus and CX-5461 provides a major improvement for overall survival in this highly aggressive mouse model of MYC-driven cancer. 
Author Manuscript Published OnlineFirst on October 21, 2015; DOI: 10.1158/2159-8290.CD-14-0673

Author manuscripts have been peer reviewed and accepted for publication but have not yet been edited.

Targeting the ribosome to treat MYC-driven lymphoma

\section{Combined inhibition of mTORC1 signaling and rDNA transcription enhances apoptosis of MYC-driven lymphoma cells}

To investigate the cellular mechanism(s) underlying this synergistic effect of inhibiting $\mathrm{PI} 3 \mathrm{~K} / \mathrm{AKT} / \mathrm{mTOR}$ signaling and rDNA transcription we analyzed the effects of combining everolimus or AKTi-1/2 with CX-5461 with respect to the induction of apoptosis in E $\mu-M y c$ lymphoma cells. Both everolimus (Fig.S2A) and AKTi-1/2 (Fig.S2B) synergized with CX-5461 to significantly increase apoptosis in cultured E $\mu-M y c$ lymphoma cells (Fig.S2C), suggesting that enhanced induction of apoptosis is a mechanism through which they cooperate to treat MYC-driven lymphoma in vivo. Similarly, combined treatment of E $\mu-M y c$ B-lymphoma-bearing mice with a single dose of everolimus plus CX-5461 for 6 hours resulted in a significant increase in cell death in the bone marrow (Fig.2C) and spleen (Fig.2D) compared to CX-5461 alone. The enhanced cell death with combination treatment correlated with increased reductions in the $\mathrm{E} \mu-M y c$ tumour (GFP-positive) cell populations in the bone marrow (Fig.2E) and spleens (Fig.2F) compared to either single agent. Furthermore combination therapy (72 hours) in mice transplanted with a different $T p 53^{\mathrm{WT}} \mathrm{E} \mu-M y c$ B-lymphoma clone also resulted in significantly increased clearance of GFP-positive $\mathrm{E} \mu-M y c$ tumor cells from the bone marrow (Fig.S2D) and a greater reduction of disease burden in the axillary lymph node (Fig.S2E) compared to CX-5461 treatment alone. Importantly, combination therapy did not adversely affect the wild-type B-cell population, with an increased proportion of GFP-negative plus B220-positive B-cells detected in the circulating blood of mice treated with CX-5461 and everolimus plus CX-5461 (Fig.S2F), consistent with the specificity of CX-5461 for tumour 
Author Manuscript Published OnlineFirst on October 21, 2015; DOI: 10.1158/2159-8290.CD-14-0673

Author manuscripts have been peer reviewed and accepted for publication but have not yet been edited.

Targeting the ribosome to treat MYC-driven lymphoma

cells we demonstrated previously (12). Together these results demonstrate that $\mathrm{AKT} / \mathrm{mTORC} 1$ inhibition and CX-5461 cooperate to enhance apoptosis of $\mathrm{E} \mu-M y c$ B-lymphoma cells in culture and in vivo, and this mechanism is likely to explain the significantly improved survival in lymphoma-bearing mice receiving combination therapy.

\section{AKT/mTORC1 inhibitors combine with CX-5461 to inhibit ribosome biogenesis and induce p53 and BMF pro-apoptotic pathways}

A functional p53-response is a key component of CX-5461-induced apoptosis (12), with E $\mu-M y c$ B-lymphoma cells generated on a $T p 53^{-/-}$background (Fig.S3A) significantly less sensitive than those with a wild-type Tp53 genotype to the induction of apoptosis by CX-5461 (Fig.S3B). Thus the ability of AKT/mTORC1 signaling blockade to reduce free RP abundance (Fig.1E) suggested that $\mathrm{PI} 3 \mathrm{~K} / \mathrm{AKT} / \mathrm{mTOR}$ pathway inhibitors might antagonize p53 activation and apoptosis induced by CX-5461 and potentially limit the cooperation between these two inhibitor classes. In contrast however, we found that the increase in p53 protein abundance induced by CX-5461 was not affected by combination with either everolimus (Fig.3A and S3C) or AKTi1/2 (Fig.S3D), nor was CX-5461 induced disruption of nucleolar morphology (Fig.3B and S3E). Importantly p53 protein accumulation in vivo following acute treatment with CX-5461 for 6 (Fig.3C) and 72 hours (Fig.3D) was not prevented or reduced in B-lymphoma bearing mice co-treated with everolimus.

Due to PI3K/AKT/mTORC1 inhibition disrupting rDNA gene transcription via a different mechanism to $\mathrm{CX}-5461(14,20,25)$, we hypothesized that the combination of both inhibitor classes would also be associated with enhanced 
Author Manuscript Published OnlineFirst on October 21, 2015; DOI: 10.1158/2159-8290.CD-14-0673

Author manuscripts have been peer reviewed and accepted for publication but have not yet been edited.

Targeting the ribosome to treat MYC-driven lymphoma

effects on rRNA synthesis. Indeed, treatment of E $\mu-M y c$ B-lymphoma cells with everolimus (Fig.3E) or AKTi-1/2 (Fig.3F) in combination with CX-5461 further suppressed rDNA gene transcription initiation rates beyond that achieved with either single agent. Importantly, the combination of everolimus and CX-5461 in vivo (2 hours) further suppressed rDNA transcription initiation in the inguinal lymph nodes of mice with transplanted E $\mu-M y c$ B-lymphoma (Fig.3G). We hypothesize that this increased potency of the combination therapy for targeting rRNA synthesis underpins the maintenance of p53 induction by CX-5461 in the combination treatment setting. Furthermore, CX5461 did not alter the increased expression of BMF protein induced by either everolimus (Fig.3H) or AKTi-1/2 (Fig.S3F). Taken together, this data supports a mechanism whereby the combination of $\mathrm{PI} 3 \mathrm{~K} / \mathrm{AKT} / \mathrm{mTOR}$ pathway inhibitors and CX-5461 potentiates the inhibition of rRNA synthesis, which is associated with enhanced E $\mu-M y c$ B-lymphoma apoptosis and the maintain induction of distinct apoptotic mechanisms (p53 and BMF).

\section{Activation of both p53 and BMF apoptotic pathways are required for the therapeutic benefit of combining everolimus and CX-5461.}

The requirement for functional p53 and BMF for cooperation between everolimus and CX-5461 to treat MYC-driven B-cell lymphoma was examined. Combination treatment did not alter the induction of apoptosis of cultured

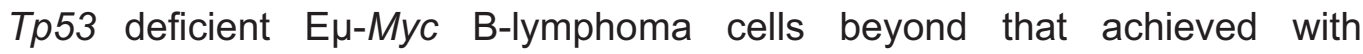
everolimus as a single agent (Fig.S4A), indicating that functional p53 expression is required for enhanced induction of cell death in culture by these agents. However, combination treatment with everolimus and CX-5461 did 
Author Manuscript Published OnlineFirst on October 21, 2015; DOI: 10.1158/2159-8290.CD-14-0673

Author manuscripts have been peer reviewed and accepted for publication but have not yet been edited.

Targeting the ribosome to treat MYC-driven lymphoma

provide a modest survival benefit beyond single agents in mice transplanted

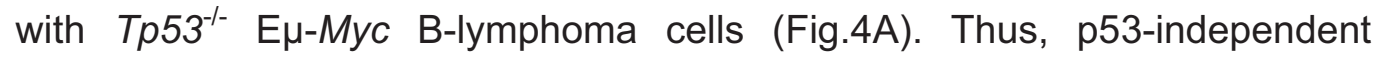
mechanisms must contribute to the therapeutic response to CX-5461 in vivo, both as a single agent and in combination with everolimus. Importantly however, the survival extension in $T p 53^{-/} \mathrm{E} \mu-M y c$ B-lymphoma provided by the combination therapy, beyond that of the single agents, was significantly less than that observed in mice transplanted with $T p 53^{\mathrm{WT}} \mathrm{E \mu}-\mathrm{Myc} \mathrm{B}-$ lymphoma (Fig.2A-B, 4D and S4B). This confirms that the p53 pathway is critical for potent cooperation between these two agents in this model.

Similar results to $T p 53^{-/-} \mathrm{E} \mu-M y c$ B-lymphoma were observed in mice transplanted with $\mathrm{Bmf}^{/-} \mathrm{E} \mu-\mathrm{Myc}$ B-lymphoma cells that either expressed wildtype p53 protein (Fig.4B) or did not express functional p53 due to a spontaneous mutation (Tp53 ${ }^{\text {Mutant; }}$ Fig.4C and S4C-D). In both cases the survival extension provided by combination treatment beyond that of the best single agent (Fig.4B: CX-5461; Fig.4C: everolimus) was significantly less than the survival extension achieved by the combination in $\mathrm{E} \mu-M y c$ B-lymphoma with both wild-type p53 and wild-type BMF (Fig.4D and S4C). Functional p53 and BMF pathways were therefore required for optimal cooperation between everolimus and CX-5461 to treat MYC-driven B-cell lymphoma in vivo although p53- and BMF-independent mechanisms also exist. Overall however, while the absence of BMF alone reduced the potency of the combination treatment regimen with respect to survival extension, the absence of functional p53 had the most dramatic effect on the ability of everolimus and 
Author Manuscript Published OnlineFirst on October 21, 2015; DOI: 10.1158/2159-8290.CD-14-0673

Author manuscripts have been peer reviewed and accepted for publication but have not yet been edited.

Targeting the ribosome to treat MYC-driven lymphoma

CX-5461 to provide a synergistic therapeutic benefit against aggressive B-cell lymphoma (Fig.4D and S4C).

\section{DISCUSSION}

We hypothesized that targeting the ribosome with combination therapy would exploit the intrinsic reliance of MYC-driven B-lymphoma cells on enhanced rates of ribosome biogenesis $(12,13,15)$ and $\mathrm{mTORC} 1 / \mathrm{eIF} 4 \mathrm{E}$-driven protein synthesis $(18,19,24)$. We found that specific inhibition of rDNA transcription initiation with CX-5461 in combination with the inhibition of key mRNA translation regulatory molecules (AKT/mTORC1) markedly improved therapeutic potency against $\mathrm{E} \mu-M y c$ B-lymphoma by independently engaging the p53 and BMF pro-apoptotic pathways respectively. Consistent with previous findings CX-5461 potently induced nucleolar disruption and p53 activation in $\mathrm{E} \mu-M y c$ B-lymphoma cells $(12,14)$ that was demonstrated here to be associated with the increased abundance of free RPs available to interact with and inhibit MDM2. In contrast, PI3K/AKT/mTOR-inhibitor mediated suppression of rDNA transcription rates occurred in the absence of nucleolar disruption and p53 pathway activation and was instead associated with the up-regulation of BMF protein. The lack of p53 stabilization following selective inhibition of mTORC1 signaling by rapamycin has been previously reported $(40,41)$, however the mechanism underpinning the absence of a nucleolar stress response despite disruption of ribosome biogenesis remained undefined. Here we demonstrate that the absence of p53 activation following AKT/mTORC1 inhibition, despite the robust reduction of rDNA transcription rates, was associated with decreased proportions of ribosomes in 
Author Manuscript Published OnlineFirst on October 21, 2015; DOI: 10.1158/2159-8290.CD-14-0673

Author manuscripts have been peer reviewed and accepted for publication but have not yet been edited.

Targeting the ribosome to treat MYC-driven lymphoma

translationally active polysomes, and reduced abundance of critical nucleolarstress related RPs (RPL11 and RPL5). This is consistent with the welldocumented roles of PI3K/AKT/mTOR pathway for the modulation of ribosome function and selective mRNA translation in addition to the regulation of rDNA transcription $(20,26,27,39)$.

The altered expression of RPL11 and RPL5 in response to treatment with both AKTi-1/2 (decreased) and CX-5461 (increased) is also consistent with a previous report suggesting the importance of an imbalance between rRNA and RP synthesis for the activation of p53 in response to the disruption of rDNA transcription (40). Specifically, the presence of free RPs in excess to rRNA, as a consequence of the selective inhibition of rDNA transcription, is intrinsic to the induction of p53 by $\mathrm{CX}-5461$, while the concomitant decrease in the synthesis of RPs and rRNA following PI3K/AKT/mTOR inhibition prevents this response. Importantly, combined treatment of B-lymphoma cells with $\mathrm{AKT} / \mathrm{mTORC} 1$ inhibitors and $\mathrm{CX}-5461$ enhanced the suppression of rDNA transcription initiation rates and hence rRNA synthesis, facilitating p53 pathway activation despite the impact that $\mathrm{PI} 3 \mathrm{~K} / \mathrm{AKT} / \mathrm{mTOR}$ signaling blockade has on protein translation and critical RP abundance. The ability of $\mathrm{PI} 3 \mathrm{~K} / \mathrm{AKT} / \mathrm{mTOR}$ signaling inhibitors to disrupt rDNA transcription at multiple points (20) in addition to RP synthesis and mRNA translation is therefore likely to be key to their capacity to potently cooperate with CX-5461 to kill MYC-driven cancer cells.

Our in vivo studies clearly showed that the activation of the p53 tumor suppressor pathway was integral for a strong therapeutic effect of combining 
CX-5461 with everolimus to treat MYC-driven B-lymphoma. BMF expression was also required for optimal combination therapy effects in vivo. However, it is clear that additional factors may also contribute to the potency of this treatment strategy, as some survival benefit was derived from combination therapy in $T p 53^{--}$and Tp53 Mutant $\mathrm{E} \mu-M y c$ clones, in direct contrast to that observed with $T p 53^{--}$B-lymphoma cells in culture. This is consistent with previous work demonstrating that the sensitivity of solid tumor cells to CX5461 is independent of p53 mutational status and is not exclusively dependent on the induction of cell death (14). Additionally, the improved in vivo efficacy provided by the combination (everolimus plus CX-5461) was associated with increased tumor cell clearance from the bone marrow compartment. This is important as early disease relapse is thought to originate from tumor cells that remain within a protective bone marrow niche $(42,43)$. Our data therefore suggests potential bone marrow-specific effects of the combination therapy are associated with the improved response. Our previous studies revealed that everolimus-mediated survival advantage was associated with the induction of cellular senescence in vivo (28). Future experiments will therefore test the possibility that this response may contribute to microenvironment-specific effects or to improved immune-system mediated clearance of B-lymphoma cells in the response to single agent therapy with CX-5461.

The identification and establishment of therapeutic approaches for MYCdriven cancer is critical given the high proportion of tumors that exhibit deregulated MYC activity and the difficulty of directly targeting transcription factors (44). While there are many emerging efforts to target dysregulated 
Author Manuscript Published OnlineFirst on October 21, 2015; DOI: 10.1158/2159-8290.CD-14-0673

Author manuscripts have been peer reviewed and accepted for publication but have not yet been edited.

Targeting the ribosome to treat MYC-driven lymphoma

MYC in cancer (reviewed in 45), current approaches are focused on the development of strategies that exploit the reliance of these malignancies on MYC-governed processes. For example, in addition to our approach of targeting the ribosome, inhibitors of bromodomain and extra-terminal (BET) proteins (e.g. JQ-1, iBET-151) that modulate RNA polymerase II-mediated transcription processes, including the expression of the c-Myc gene and downstream targets of MYC $(46,47)$. These inhibitors have shown efficacy in pre-clinical models of MYC-driven cancer and proceeded to clinical trial (47, 48). While these inhibitors do not mediate therapeutic responses exclusively via disruption of MYC-directed transcription programs, it will be of great interest to compare their efficacy with combination strategies targeting ribosome and protein synthesis in MYC-driven malignancies, thus allowing MYC to be targeted at yet another level in cancer cells.

We propose that clinical trials of this combination therapy should begin with a focus on hematological cancers. Pre-clinical studies demonstrated that hematological malignancies are particularly sensitive to CX-5461 $(12,14)$, with CX-5461 progressing to Phase I trials in patients with refractory blood cancers (ACTRN12613001061729). In addition, inhibitors of PI3K/AKT/mTOR signaling exhibit single agent efficacy in mouse models of lymphoma and multiple myeloma $(18,27-29)$ and have been approved for treatment of hematological malignancies, including the PI3Kס inhibitor idelalisib for B-cell Iymphoma and chronic lymphocytic leukemia (CLL) and the mTORC1 inhibitor temsirolimus for mantle cell lymphoma $(43,49)$. Furthermore, this work has established the importance of Tp53 and Bmf for potent cooperation between everolimus and CX-5461 to treat MYC-driven lymphoma in vivo. 
Author Manuscript Published OnlineFirst on October 21, 2015; DOI: 10.1158/2159-8290.CD-14-0673

Author manuscripts have been peer reviewed and accepted for publication but have not yet been edited.

Targeting the ribosome to treat MYC-driven lymphoma

Hematological malignancies are associated with a relatively low frequency of Tp53 deficiency (<20 percent) in contrast to solid tumours, of which over 60 percent possess Tp53 mutations (reviewed in 50). Additionally, BMF protein is widely expressed in hematological cells and has been shown to be important for the induction of tumour cell death malignanices such as acute lymphatic leukemia (ALL) and CLL upon treatment with glucocorticoids as well as histone deacetylase (HDAC) inhibitors (51-53). Taken together with our current study, these observations indicate that the key elements to underpin robust therapeutic responses to combination therapy with PI3K/AKT/mTOR inhibitors and CX-5461 are in place in Tp53 wild type hematological cancers.

Despite some successes, many PI3K/AKT/mTOR pathway inhibitors have exhibited poor efficacy in the clinic despite robust pre-clinical efficacy (54). Importantly, our findings suggest that the efficacy of PI3K/AKT/mTOR inhibitors may be markedly improved by combination with selective inhibitors of rDNA transcription such as CX-5461 or one of the growing list of Pol I transcription inhibitors currently under development (37). Strikingly, this therapeutic regime is well tolerated by the animals and remained selective for tumor cells with no negative effect against the wild-type B cell population observed. Furthermore, another tantalizing possibility arising from this study is that targeting a housekeeping process such as ribosome biogenesis and targeting growth networks at multiple points will make it more difficult for tumour cells to bypass inhibition. This approach may therefore overcome at least some of the resistance mechanisms driven by tumor heterogeneity. 
Author Manuscript Published OnlineFirst on October 21, 2015; DOI: 10.1158/2159-8290.CD-14-0673

Author manuscripts have been peer reviewed and accepted for publication but have not yet been edited.

Targeting the ribosome to treat MYC-driven lymphoma

In summary, inhibitors of AKT/mTOR signaling and rDNA transcription potently cooperate to treat $T p 53^{\mathrm{WT}}$ and $B m f^{\mathrm{NT}} \mathrm{E} \mu-M y c$ B-cell lymphoma, enhancing the induction of apoptosis and more than doubling the survival of mice with transplanted B-lymphoma. This potent improvement in efficacy is characterized by increased inhibition of rDNA transcription and mTORC1/elF4E-dependent protein synthesis leading to induction of both p53 and BMF-dependent apoptotic pathways. Importantly this work underscores the concept that MYC driven tumors are addicted to multiple regulatory steps associated with ribosome synthesis and protein synthesis. It establishes the coordinated inhibition of key players in the complex network controlling the ribosome as a novel and potent strategy for the treatment of cancers driven by dysregulated MYC activity.

\section{METHODS}

Detailed methods are provided in the supplementary material.

\section{Cell culture and reagents}

Eн-Myc clonal B-lymphoma cell lines (clone \#4242, \#107, \#3239, \#3391, \#14 and \#31) were kindly provided by $\mathrm{R}$. Johnstone, Peter MacCallum Cancer Centre, East Melbourne 3002, VIC, Australia between January 2010 and December 2014 and were cultured as described previously $(12,44)$. All E $\mu-$ Myc clonal B-lymphoma cell lines utilized were generated from the lymphomas of transgenic $\mathrm{E} \mu-M y c$ mice and therefore have not been authenticated. AKTi-1/2 (124017) was from MERCK (Kenilworth, NJ, USA); KU-0063794 (KU-63794 - S1226) and everolimus (S1120) were from Selleckchem. NVP-BEZ-235 (BEZ-235) was provided by Novartis (Basel, 
Author Manuscript Published OnlineFirst on October 21, 2015; DOI: 10.1158/2159-8290.CD-14-0673

Author manuscripts have been peer reviewed and accepted for publication but have not yet been edited.

Targeting the ribosome to treat MYC-driven lymphoma

Switzerland) and CX-5461 was provided by Cylene Pharmaceuticals and Senhwa Biosciences (San Diego, CA, USA). 10mM stocks of AKTi-1/2, KU0063794 and NVP-BEZ-235 were prepared in DMSO. For use in vitro $1 \mathrm{mM}$ stocks of everolimus were prepared in $100 \%$ ethanol and $10 \mathrm{mM}$ stocks of CX5461 in $50 \mathrm{mM} \mathrm{NaH} \mathrm{PO}_{4}$. For use in vivo everolimus was given daily at $5 \mathrm{mg} / \mathrm{kg}$ (oral gavage) in DMSO (5 percent) and 1 percent methylcellulose (95 percent) and CX-5461 every 3 days at $30-40 \mathrm{mg} / \mathrm{kg}$ (oral gavage) in $25 \mathrm{mM}$ $\mathrm{NaH}_{2} \mathrm{PO}_{4}(\mathrm{pH} 4.5)$.

\section{Animal Experiments}

All animal experiments were performed with approval from the Peter MacCallum Cancer Centre Animal Experimentation Ethics Committee (Project E462). 6 - 8 week old male C57BI/6 mice (Walter and Eliza Hall Institute, Parkville, VIC, Australia) were intravenously injected with $2 \times 10^{5} \mathrm{E \mu}-\mathrm{Myc} \mathrm{B}-$ lymphoma cells and treated with pharmacological inhibitors from 10 days post-injection (survival analyses) or on day 13 or 14 post-injection (acute analysis). For survival analyses treatment of mice continued until an ethical end-point was reached (Supplementary Materials and Methods). White blood cells, axillary lymph node cells and bone marrow cells were analyzed for GFP and B220 (CD45R) expression or fixed with 95\% ethanol and stained with PI for SubG $_{1}$ analysis (Supplementary Materials and Methods).

\section{Protein and RNA analysis}

Protein was extracted with SDS-lysis or Rac-lysis buffer (Supplementary Table 1), separated by SDS-PAGE, transferred to PDVF membranes, immunoblotted with primary and HRP-conjugated secondary antibodies 
Author Manuscript Published OnlineFirst on October 21, 2015; DOI: 10.1158/2159-8290.CD-14-0673

Author manuscripts have been peer reviewed and accepted for publication but have not yet been edited.

Targeting the ribosome to treat MYC-driven lymphoma

(Supplementary Table 2) and protein visualized by enhanced chemiluminescence (Perkin Elmer NEL104001EA) and X-ray film (Fujifilm SuperRX). RNA was extracted with the Bioline Isolate RNA Kit (BIO 520-44) with $\alpha^{32}$ P-UTP riboprobe added to allow for RNA recovery correction. cDNA was synthesized with SuperScript III (Invitrogen 18080-044) from template RNA equivalent to either equal cell number or RNA concentration and analyzed by quantitative real-time polymerase chain reaction (qRT-PCR; Supplementary Table 3). For MDM2 immunoprecipitation (IP), protein was extracted with NP-40 lysis buffer (Supplementary Table 1), incubated with $3 \mu \mathrm{g}$ MDM2 antibody cocktail and IP isolated with MagnaChIP beads (Millipore 16661). For analysis of free RPs cells were incubated with $10 \mu \mathrm{g} / \mu \mathrm{L}$ cycloheximide (Sigma Aldrich C-1988) for 15 minutes and protein extracted with hypotonic lysis buffer (Supplementary Table 1). Protein lysates equivalent to equal cell number were concentrated, fractionated through $1.8 \mathrm{M}$ sucrose. Post-spin supernatant and pellet fractions were isolated. For polysome profiling, cells were incubated with $10 \mu \mathrm{g} / \mu \mathrm{L}$ cycloheximide and protein extracted with hypotonic lysis buffer. Protein lysates equivalent to equal cell number were centrifuged through $10-40 \%$ sucrose, separated and analyzed with ISCO Tris ${ }^{\text {TM }}$ and UA-6 UV/VIS detector (Teledyne, Thousand Oaks, CA, USA). Sub-polysome:polysome ratios were determined by measuring the area under the curve as described previously (49).

\section{Immunofluorescence}

Cells were fixed ( $2 \%$ paraformaldehyde), cytospun onto Superfrost Plus ${ }^{\circledR}$ microscope slides and stained with a-fibrillarin (Abcam 5821) and 594conjugated secondary antibody (Life Technologies A-11012). Slides were 
Author Manuscript Published OnlineFirst on October 21, 2015; DOI: 10.1158/2159-8290.CD-14-0673

Author manuscripts have been peer reviewed and accepted for publication but have not yet been edited.

Targeting the ribosome to treat MYC-driven lymphoma

analyzed with the Olympus BX-61, images captured with SPOT Advanced software (4.6.4.3 Diagnostic Instruments) and analyzed with ImageJ software (1.47v, NIH, USA).

\section{Flow Cytometry}

For Annexin-V and propidium iodide $(\mathrm{PI})$ analysis cells were stained with Annexin-V-APC (BD Pharmigen 550474) and $1 \mu \mathrm{g} / \mathrm{mL}$ PI (Sigma Aldrich 81845) and analyzed with the BD LSR. For SubG 1 analysis cells were fixed with $95 \%$ ethanol, stained with $50 \mu \mathrm{g} / \mathrm{mL}$ PI and analyzed with the BD Canto II. Flow cytometry data was analyzed with FCSExpress software (De Novo, Los Angeles, CA, USA).

\section{Statistical tests}

Student t-tests (two-tailed), two-way ANOVA, Mantel-Cox and GehanBreslow-Wilcoxin tests were performed with GraphPad Prism Software (Version 6, La Jolla, CA, USA). Combination drug index (CDI) was determined as described previously (55).

\section{SUPPLEMENTARY MATERIAL}

Supplementary material consists of supplementary materials and methods, tables (3) and figures (4).

\section{ACKNOWLEDGEMENTS}

We thank Kerry Ardley, Susan Jackson and Rachael Walker (Peter MacCallum Centre) for technical assistance with animal experiments. We thank the Peter MacCallum Cancer Centre Animal Facility, FACS facility, Histology and Microscopy Core, Laboratory Services and Media Kitchen.

\section{AUTHOR CONTRIBUTIONS}


Author Manuscript Published OnlineFirst on October 21, 2015; DOI: 10.1158/2159-8290.CD-14-0673

Author manuscripts have been peer reviewed and accepted for publication but have not yet been edited.

Targeting the ribosome to treat MYC-driven lymphoma

Conception and design: J.R. Devlin, K.M. Hannan, C. Cullinane, R.D. Hannan, R.B. Pearson

Development of methodology: J.R. Devlin, K.M. Hannan, N. Hein, C. Cullinane, E. Kusnadi, A. George, J. Shortt, M.J. Bywater, E. Sanij, G. Poortinga D. Drygin, S. O’Brien, R. W. Johnstone

Acquisition of data (including generation and provision of cell lines): J.R. Devlin, K.M. Hannan, N. Hein, E. Kusnadi, G. Ng, J. Kang, J. Shortt, M.J. Bywater

Analysis and interpretation of data: J.R. Devlin, K.M. Hannan, N. Hein, C. Cullinane, E.Kusnadi A. George, E. Sanij, G. Poortinga G.A. McArthur, R.D. Hannan, R.B. Pearson

Writing, review and/or revision of the manuscript: J.R. Devlin, K.M. Hannan, N. Hein, C. Cullinane, A. George, E. Sanij, G. Poortinga, D. Drygin, S. O'Brien, R.W. Johnstone, G.A. McArthur, R.D. Hannan, R.B. Pearson

Administrative, technical, or material support (i.e., reporting or organizing data, constructing databases): J.R. Devlin, C. Cullinane, R.D. Hannan, R.B. Pearson

Study Supervision: K.M.Hannan, G.A. McArthur, R.D. Hannan. R.B. Pearson

\section{REFERENCES}

1. Baker V, Borst M, Dixon D, Hatch K, Shingleton H, Miller D. c-myc amplification in ovarian cancer. Gynecol Oncol. 1990;38:340-2.

2. $\quad$ Dang CV. MYC on the path to cancer. Cell. 2012;149:22-35.

3. Delgado MD, Leon J. Myc roles in hematopoiesis and leukemia. Genes Cancer. 2010;1:605-16.

4. Horiuchi D, Kusdra L, Huskey N, Chandriani S, Lenburg M, Gonzalez-Angulo A, et al. MYC pathway activation in triple-negative breast cancer is synthetic lethal with CDK inhibition. Journal Exp Med. 2012;209:679-96.

5. Koh C, Bieberich C, Dang C, Nelson W, Yegnasubramaian S, De Marzo A. MYC and Prostate Cancer. Genes Cancer. 2010;1:617-28.

6. Zhuang D, Mannava S, Grachtchouk V, Tang W, Patil S, Wawrzyniak J, et al. C-MYC overexpression is required for continuous suppression of oncogeneinduced senescence in melanoma cells. Oncogene. 2008;27:6623-34.

7. Ji H, Wu G, Zhan X, Nolan A, Koh C, De Marzo A, et al. Cell-type independent MYC target genes reveal a primordial signature involved in biomass accumulation. PLoS One. 2011;6:e26057.

8. Dang C. MYC, metabolism, cell growth, and tumorigenesis. Cold Spring Harb Perspect Med. 2013;3:pii: a014217.

9. Poortinga G, Quinn L, Hannan R. Targeting RNA polymerase I to treat MYCdriven cancer. Oncogene. 2015;34:403-12.

10. Poortinga G, Wall M, Sanij E, Siwicki K, Ellul J, Brown D, et al. c-MYC coordinately regulates ribosomal gene chromatin remodeling and Pol I availability during granulocyte differentiation. Nucleic Acids Res. 2011;39:3267-81.

11. Poortinga G, Hannan K, Snelling H, Walkley C, Jenkins A, Sharkey K, et al. MAD1 and C-MYC regulate UBF and rDNA transcription during granulocyte differentiation. EMBO J. 2004;23:3325-35.

12. Bywater M, Poortinga G, Sanij E, Hein N, Peck A, Cullinane C, et al. Inhibition of RNA polymerase I as a therapeutic strategy to promote cancer-specific activation of p53. Cancer Cell. 2012;22:51-65.

13. Bywater M, Pearson R, McArthur G, Hannan R. Dysregulation of the basal RNA polymerase transcription apparatus in cancer. Nat Rev Cancer. 2013;13:299-314.

14. Drygin D, Lin A, Bliesath J, Ho C, O'Brien S, Proffitt C, et al. Targeting RNA polymerase I with an oral small molecule CX-5461 inhibits ribosomal RNA synthesis and solid tumor growth. Cancer Res. 2011;71:1418-30. 
Author Manuscript Published OnlineFirst on October 21, 2015; DOI: 10.1158/2159-8290.CD-14-0673

Author manuscripts have been peer reviewed and accepted for publication but have not yet been edited.

Targeting the ribosome to treat MYC-driven lymphoma

15. Hannan RD, Drygin D, Pearson RB. Targeting RNA polymerase I transcription and the nucleolus for cancer therapy. Expert Opin Ther Targets. 2013;17:873-8.

16. Hein N, Hannan K, George A, Sanij E, Hannan R. The nucleolus: an emerging target for cancer therapy. Trends Mol Med. 2013;19:643-54.

17. Quin J, Devlin J, Cameron D, Hannan K, Pearson R, Hannan R. Targeting the nucleolus for cancer intervention. Biochim Biophys Acta. 2014;1842:80216.

18. Pourdehnad M, Truitt M, Siddiqi I, Ducker G, Shokat K, Ruggero D. Myc and mTOR converge on a common node in protein synthesis control that confers synthetic lethality in Myc-driven cancers. Proc Natl Acad Sci USA. 2013;110:11988-93.

19. Ruggero D, Montanaro L, Ma L, Xu W, Londei P, Cordon-Cardo C, et al. The translation factor elF-4E promotes tumor formation and co-operates with cMyc in lymphomagenesis. Nat Med. 2004;10:484-6.

20. Chan J, Hannan K, Riddel K, Ng P, Peck A, Lee R, et al. AKT promotes rRNA synthesis and cooperates with c-MYC to stimulate ribosome biogenesis in cancer. Sci Signal. 2011;4:ra56.

21. Hannan KM, Sanij E, Rothblum LI, Hannan RD, Pearson RB. Dysregulation of RNA polymerase I transcription during disease. Biochimi Biophys Acta. 2013;1829:342-60.

22. Jefferies H, Fumagalli S, Dennis P, Reinhard C, Pearson R, Thomas G. Rapamycin suppresses 5'TOP mRNA translation through inhibition of p70s6k. EMBO J. 1997;16:3693-704.

23. Sheppard K, Kinross K, Solomon B, Pearson R, Phillips W. Targeting PI3 kinase/AKT/mTOR signaling in cancer. Crit Rev Oncog. 2012;17:69-95.

24. Ma XM, Blenis J. Molecular mechanisms of mTOR-mediated translational control. Nat Rev Mol Cell Biol. 2009;10:307-18.

25. Hannan K, Brandenburger Y, Jenkins A, Sharkey K, Cavanaugh A, Rothblum $\mathrm{L}$, et al. mTOR-dependent regulation of ribosomal gene transcription requires S6K1 and is mediated by phosphorylation of the carboxy-terminal activation domain of the nucleolar transcription factor UBF. Mol Cell Biol. 2003;23:886277.

26. Jastrzebski K, Hannan K, Tchoubrieva E, Hannan R, Pearson R. Co-ordinate regulation of ribosome biogenesis and function by the ribosomal protein S6 kinase, a key mediator of mTOR function. Growth Factors. 2007;25:209-26.

27. Devlin J, Hannan $\mathrm{K}, \mathrm{Ng}$ P, Bywater M, Shortt J, Cullinane C, et al. AKT signalling is required for ribosomal RNA synthesis and progression of EuMYC B-cell lymphoma in vivo. FEBS J. 2013;280:5307-16.

28. Wall M, Poortinga G, Stanley K, Lindermann R, Bots M, Chan J, et al. The mTORC1 inhibitor everolimus prevents and treats Eu-Myc lymphoma by restoring oncogene-induced senescence. Cancer Discov. 2013;3:82-95.

29. Shortt J, Martin B, Newbold A, Hannan K, Devlin J, Baker A, et al. Combined inhibition of PI3K-related DNA damage response kinases and mTORC1 induces apoptosis in MYC-driven B-cell lymphomas. Blood. 2013;121:296474.

30. Barna M, Pusic A, Zollo O, Costa M, Kondrashov N, Rego E, et al. Suppression of Myc oncogenic activity by ribosomal protein haploinsufficiency. Nature. 2008;456:971-5.

31. Hsieh A, Truitt $M$, Ruggero D. Oncogenic AKTivation of translation as a therapeutic target. Brit J Cancer. 2011;105:329-36.

32. Shah N, Kasap C, Weier C, Balbas M, Nicoll J, Bleickardt E, et al. Transient potent BCR-ABL inhibition is sufficient to commit chronic myeloid leukemia cells irreversibly to apoptosis. Cancer Cell. 2008;14:485-93. 
Author Manuscript Published OnlineFirst on October 21, 2015; DOI: 10.1158/2159-8290.CD-14-0673

Author manuscripts have been peer reviewed and accepted for publication but have not yet been edited.

Targeting the ribosome to treat MYC-driven lymphoma

33. Flaherty K, Infante J, Daud A, Gonzalez R, Kefford R, Sosman J, et al. Combined BRAF and MEK inhibition in melanoma with BRAF V600 mutations. N Engl J Med. 2012;367:1694-703.

34. Zhang $\mathrm{Y}, \mathrm{Lu} \mathrm{H}$. Signaling to p53: ribosomal proteins find their way. Cancer Cell. 2009;16:369-77.

35. Dutt S, Narla A, Lin K, Mullally A, Abayasekara N, Megerdichian C, et al. Haploinsufficiency for ribosomal protein genes causes selective activation of p53 in human erythroid progenitor cells. Blood. 2011;117:2567-76.

36. Drygin D, O'Brien S, Hannan R, McArthur G, Von Hoff D. Targeting the nucleolus for cancer specific activation of p53. Drug Discov Today. 2014;19:259-65.

37. Woods S, Hannan K, Pearson R, Hannan R. The nucleolus as a fundamental regulator of the p53 response and a new target for cancer therapy. Biochim Biophys Acta. 2014;doi: 10.1016/j.bbagrm.2014.10.007:[Epub ahead of print].

38. Silvera D, Formenti S, Scheider R. Translational control in cancer. Nat Rev Cancer. 2010;10:254-66.

39. Grepsi F, Soratroi C, Krumschnabel G, Sohm B, Ploner C, Geley S, et al. $\mathrm{BH} 3-$ only protein Bmf mediates apoptosis upon inhibition of CAP-dependent protein synthesis. Cell Death Differ. 2010;17:1672-83.

40. Donati G, Bertoni S, Brighenti E, Vici M, Trere D, Volarevic S, et al. The balance between rRNA and ribosomal protein synthesis up- and downregulates the tumour suppressor p53 in mammalian cells. Oncogene. 2011;30:3274-88.

41. Kao C, Hsu H, Chen H, Cheng T. Rapamycin increases the p53/MDM2 protein ratio and p53-dependent apoptosis by translational inhibition of $\mathrm{mdm} 2$ in cancer cells. Cancer Lett. 2009;286:250-9.

42. Hewett $\mathrm{Y}$, Uprety $\mathrm{D}$, Shah $\mathrm{B}$. Idelalisib - a PI3Kס targeting agent for B-cell malignancies. J Oncol Pharm Pract. 2015;Epub ahead of print:pii: 107855215572933.

43. Sanford D, Wierda W, Burger J, Keating M, O'Brien S. Three newly approved drugs for chronic lymphocytic leukemia: Incorporating Ibrutinib, Idelalisib and Obinutuzumab into clinical practice. Clin Lymphoma Myeoloma Leuk. 2015;15:385-91.

44. Shortt J, Johnstone RW. Oncogenes in cell survival and cell death. Cold Spring Harb Perspect Biol. 2012;4.

45. McKeown M, Bradner J. Therapeutic strategies to inhibit MYC. Cold Spring Harb Perspect Med. 2014;4:pii: a014266.

46. Zuber J, Shi J, Wang E, Rappaport A, Herrmann H, Sison E, et al. RNAi screen identifies Brd4 as a therapeutic target in acute myeolid leukaemia. Nature. 2011;478:524-8.

47. Delmore J, Issa $G$, Lemieux $M$, Rahl $P$, Shi J, Jacobs $H$, et al. BET bromodomain inhibition as a therapeutic strategy to target c-Myc. Cell. 2011;146:904-17.

48. Dawson M, Prinjha R, Dittman A, Giotopoulos G, Bantscheff M, Chan W, et al. Inhibition of BET recruitment to chromatin as an effective treatment for MLLfusion leukaemia. Nature. 2011;478:529-33.

49. Bouabdallah K, Ribrag V, Terriou L, Soria J, Delarue R. Temsirolimus in the treatment of mantle cell lymphoma: frequency and management of adverse effects. Curr Opin Oncol. 2013;25:S1-S12.

50. Cheung K, Horsman D, Gascoyne R. The significance of TP53 in lymphoid malignancies: mutation prevelence, regulation, prognostic impact and potential as a therapeutic target. Brit J Haemat. 2009;146:257-69.

51. Zhang $\mathrm{Y}$, Adachi M, Kawamura R, Imai K. Bmf is a possible mediator in histone deacetylase inhibitors FK228 and CBHA-induced apoptosis. Cell Death Differ. 2006;13:129-40. 
Author Manuscript Published OnlineFirst on October 21, 2015; DOI: 10.1158/2159-8290.CD-14-0673

Author manuscripts have been peer reviewed and accepted for publication but have not yet been edited.

Targeting the ribosome to treat MYC-driven lymphoma

52. Ploner C, Rainer J, Niederegger H, Eduardoff M, Villunger A, Geley S, et al. The BCL2 rheostat in glucocorticoid-induced apoptosis of acute lymphoblastic leukemia. Leukemia. 2008;22:370-7.

53. Pinon J, Labi V, Egle A, Villunger A. Bim and Bmf in tissue homeostasis and malignant disease. Oncogene. 2008;27:S41-S52.

54. Markman B, Tao JJ, Scaltriti M. PI3K pathway inhibitors: better not left alone. Curr Pharm Des. 2013;19:895-906.

55. Nahi H, Lehmann S, Mollgard L, Bengtzen S, Selivanova G, Wiman K, et al. Effects of PRIMA-1 on chronic lymphocytic leukaemia cells with and without hemizygous p53 deletion. Brit J Haemat. 2004;127:285-91.

\section{FIGURES}

Figure 1: PI3K/AKT/mTOR pathway inhibition suppresses rDNA transcription and induces BMF expression independent of p53 activation and nucleolar disruption.

(A) qRT-PCR and (B) western analysis of E $\mu-M y c$ B-lymphoma cells (clone \#4242) treated as indicated for 3 hours. (C) Immunofluorescence analysis of E $\mu-M y c$ B-lymphoma cells (clone \#4242 MSCV Cherry Bcl-2) treated as indicated for 3 hours. (D) Immunoprecipitation (IP) of MDM2 from protein lysates isolated from E $\mu-M y c$ B-lymphoma cells (clone \#4242 MSCV Cherry $B c /-2)$ treated as indicated for 1 hour. (E) Western analysis of protein isolated from E $\mu$-Myc B-lymphoma cells (clone \#4242 MSCV Cherry Bcl-2) treated as indicated for 3 hours and fractionated through a sucrose cushion. Free RP protein abundance was normalized to input and fold change over vehicle was determined. (F) Polysome profiles of lysates isolated from E $\mu-M y c$ Blymphoma cells (clone \#4242 MSCV Cherry Bcl-2) treated as indicated for 3 hours. Sub-polysome:polysome ratio was determined by measuring the area under the curve. (G) Western analysis of EM-Myc B-lymphoma cells (clone $4242 \mathrm{MSCV}$ Cherry $\mathrm{Bcl}-2$ ) treated as indicated for 24 hours. BMF protein abundance was normalized to $\alpha$-Tubulin or $\beta$-Actin and fold change over vehicle was determined. Graphs represent mean $+/-$ SEM of $n=3$. Western 
Targeting the ribosome to treat MYC-driven lymphoma

blots, immunofluorescence figures and polysome profiles are representatives of 3 independent experiments. Scale bar is $5 \mu \mathrm{m}$ and ${ }^{*} p<0.05,{ }^{* *} p<0.01$ and ${ }^{* * *} p<0.001$. Data was analyzed by student t-test.

Figure 2: Combined inhibition of mTORC1 signaling and rDNA transcription extends survival of mice with transplanted MYC-driven Blymphoma.

Kaplan-Meier curve of wild-type C57BI/6 mice transplanted with $\mathrm{E} \mu-M y c$ Blymphoma cells (A - clone \#4242 MSCV Gfp; B - clone \#107 MSCV Gfp) treated with Everolimus (5mg/kg qd), CX-5461 (35mg/kg q3d) and combination. Proportion of $\mathrm{SubG}_{1}$ cells present in the (C) bone marrow and (D) spleens of transplanted wild-type mice treated as indicated. Proportion of GFP-positive Eu-Myc B-lymphoma cells (clone \#4242 MSCV Gfp) cells present in the (E) bone marrow and (F) spleens of transplanted wild-type mice treated as indicated. Kaplan-Meier curves represent 9 or 10 mice per group. Graphs represent mean +/- SEM of 3 mice per group $(\mathbf{C}-\mathbf{F})$. Data was analyzed by log-rank (Mantel-Cox) and Gehan-Breslow-Wilcoxin tests (A - B) and student t-test $(\mathbf{C}-\mathbf{F}) .{ }^{*} p<0.05,{ }^{* *} p<0.01$.

Figure 3: Maintained activation of p53 and BMF pro-apoptotic pathways in response to combined inhibition of AKT/mTORC1 signaling and rDNA transcription.

(A) Western analysis of $\mathrm{E} \mu-M y c$ B-lymphoma cells (clone \#4242) treated as indicated for 24 hours. (B) Immunofluorescence analysis of E $\mu-M y c$ Blymphoma cells (clone \#4242 MSCV Cherry Bcl-2) treated as indicated for 3 
Targeting the ribosome to treat MYC-driven lymphoma

hours. (C) Western analysis of protein lysates isolated from the inguinal lymph nodes of mice with transplanted $\mathrm{E} \mu-M y c$ B-lymphoma cells (clone \#4242 MSCV Gfp) treated as indicated for 6 hours. (D) Western analysis of protein lysates isolated from the bone marrow of mice with transplanted $\mathrm{E} \mu-\mathrm{Myc} \mathrm{B}$ lymphoma cells (clone \#107 MSCV Gfp) treated as indicated for 72 hours. qRT-PCR analysis of E $\mu-M y c$ B-lymphoma cells (clone \#4242) treated as indicated for (E) 24 and (F) 6 hours. (G) qRT-PCR analysis of inguinal lymph nodes isolated from mice with transplanted $\mathrm{E} \mu-M y c$ B-lymphoma cells (clone \#4242 MSCV Gfp) treated as indicated for 2 hours. (H) Western analysis of E $\mu-M y c$ B-lymphoma cells (clone 4242 MSCV Cherry Bcl-2) treated indicated for 24 hours. BMF protein abundance was normalized to $\beta$-Actin and fold change over vehicle was determined. Graphs represent mean $+/-$ SEM of $n=3$ $(F, H), n=4(E)$ or 3 mice per group $(G)$. Western blots are representative of $(A$, H) 3 independent experiments, (C) 3 mice or (D) 5 mice per group. Immunofluorescence figures are representative of 3 independent experiments and scale bar is $5 \mu \mathrm{m}$. n.s, non-significant, ${ }^{*} p<0.05$, ${ }^{* * *} p<0.001$. Data was analyzed by two-way ANOVA (E, F) and student t-test ( $G$ and $H$ ).

\section{Figure 4: p53 and BMF mediates potent cooperation between}

Everolimus and CX-5461 for the treatment of MYC-driven B-lymphoma.

Kaplan-Meier curve of wild-type C57BI/6 mice transplanted with $\mathrm{E} \mu-M y c$ Blymphoma cells (A - clone \#3239 $\left(\right.$ Tp53 $\left.{ }^{-/-}\right)$; B - clone \#14 $\left.\left(B m f^{--}\right)\right)$treated with Everolimus (5mg/kg qd), CX-5461 (35mg/kg q3d) and combination. (C) Kaplan-Meier curve of wild-type C57BI/6 Ptprca mice transplanted with E $\mu$ Myc B-lymphoma cells (clone \#31 (Tp53 $\left.{ }^{\text {mutant }} ; \mathrm{Bmf}^{--}\right)$) treated with Everolimus 
Author Manuscript Published OnlineFirst on October 21, 2015; DOI: 10.1158/2159-8290.CD-14-0673

Author manuscripts have been peer reviewed and accepted for publication but have not yet been edited.

Targeting the ribosome to treat MYC-driven lymphoma

(5mg/kg qd), CX-5461 (30mg/kg q3d) and combination. 30mg/kg and $35 \mathrm{mg} / \mathrm{kg}$ CX-5461 had no difference in therapeutic efficacy against

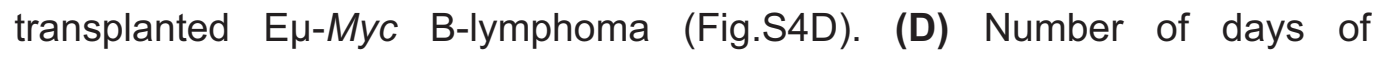
extension in survival provided by combined Everolimus + CX-5461 treatment compared to that of the best single agent. Curves represent 8 mice per group. Graph represents mean $+/-$ SEM of $n=8-10$ mice. ${ }^{* *} p<0.01$ and ${ }^{* * *} p<0.001$. Data was analyzed by student t-test. 


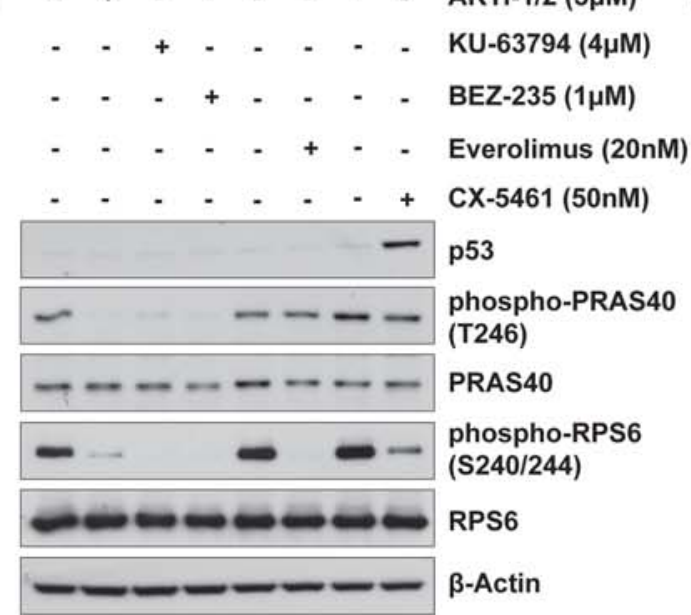

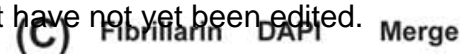

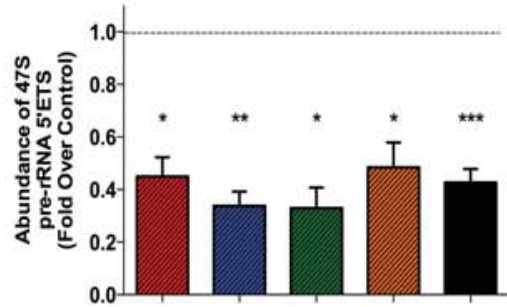

AKTi-1/2 (5」M) KU-63794 (4UM) BEZ-235 (1 $1 \mu \mathrm{M})$ Everolimus (20nM) CX-5461 (50nM)
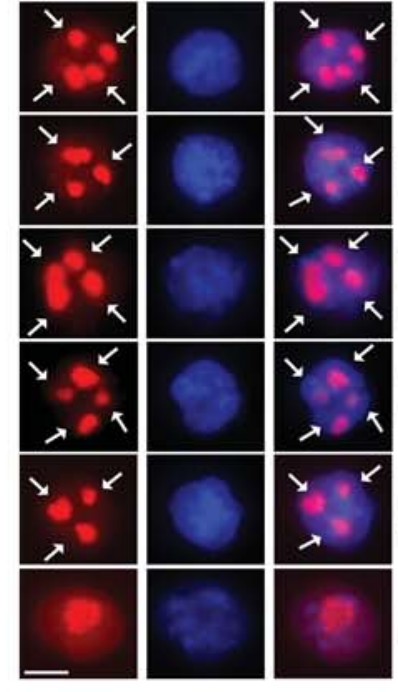

Control

$(0.1 \%$ DMSO)

AKTi-1/2 $(5 \mu \mathrm{M})$

Control $\left(2 \times 10^{6}\right.$ EtOH) Everolimus (20nM)

Control $(0.25 \mu \mathrm{M}$ $\mathrm{NaH}_{2} \mathrm{PO}_{4}$ )

CX-5461 (50nM)
(D)

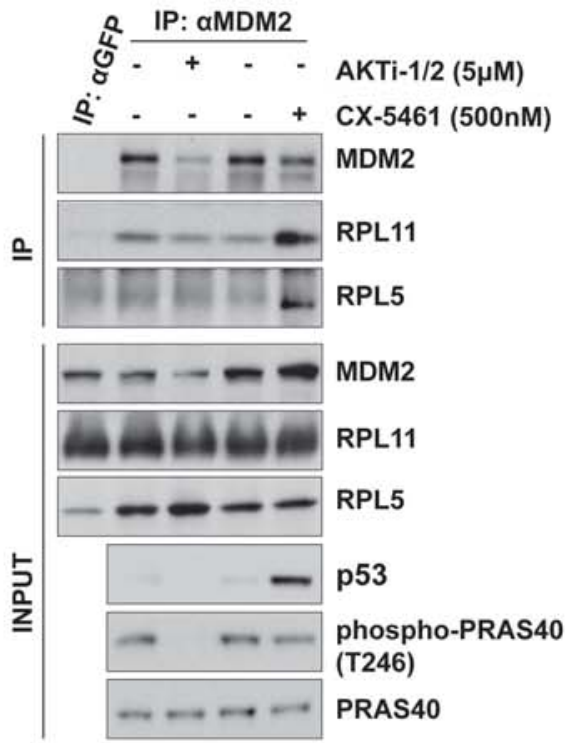

(F)

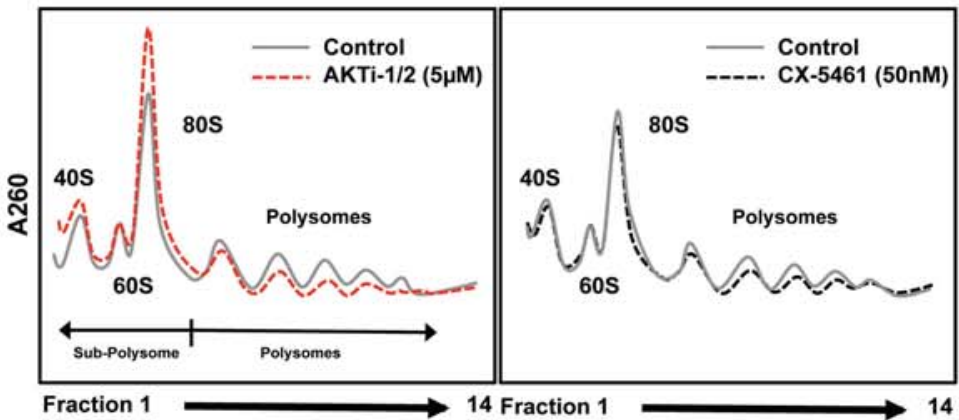

(G)

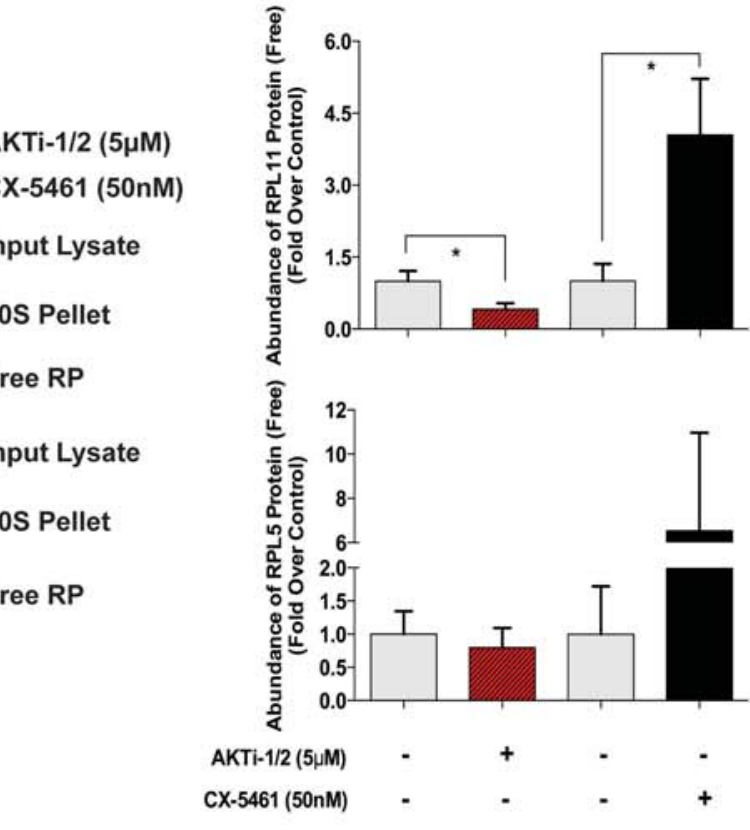

(E)

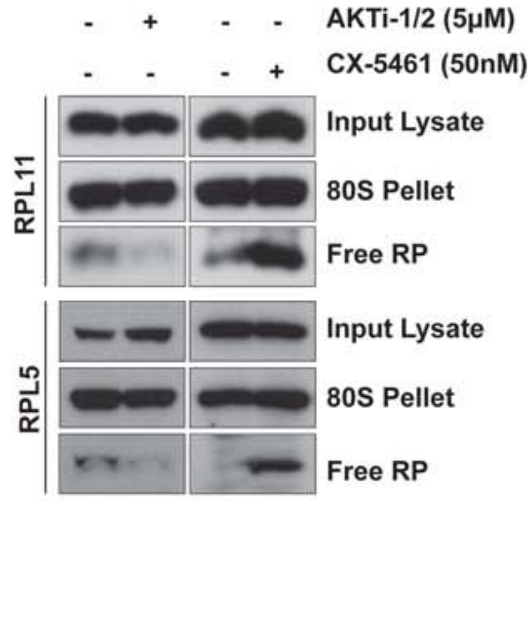

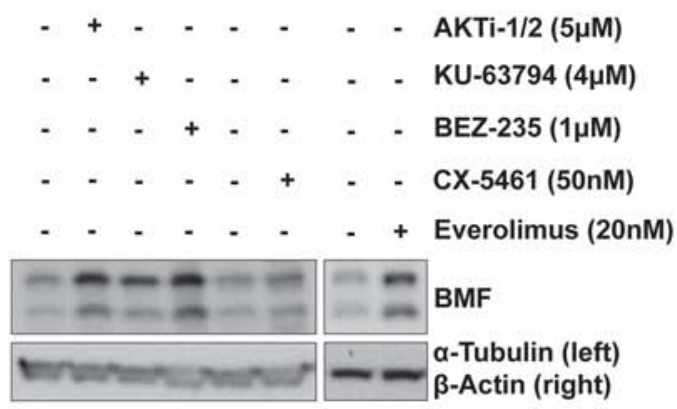

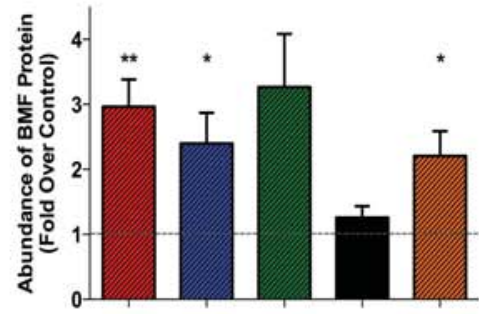

AKTi-1/2 (5uM) CX-5461 (50nM) 


\section{Figure 2}

(A)

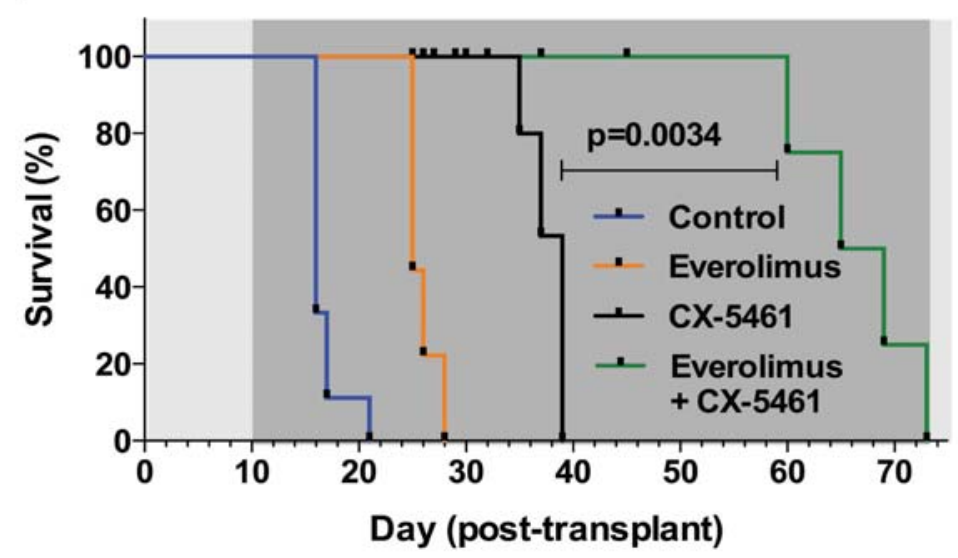

(C)

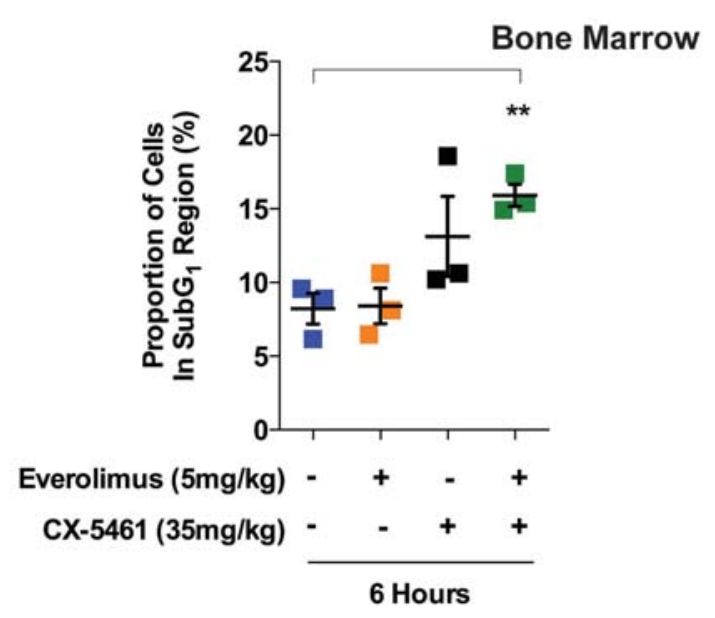

(E)

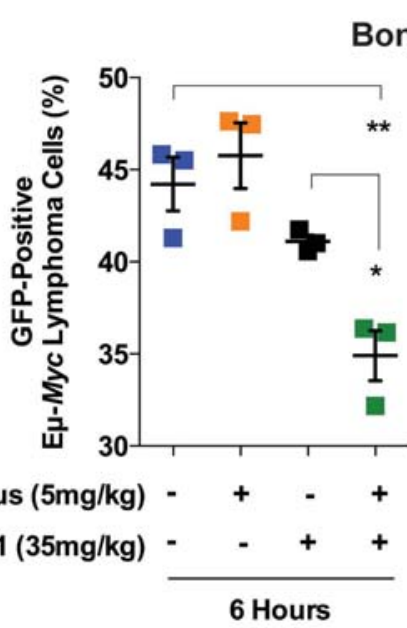

Everolimus (5mg/kg) - + - +
(B)

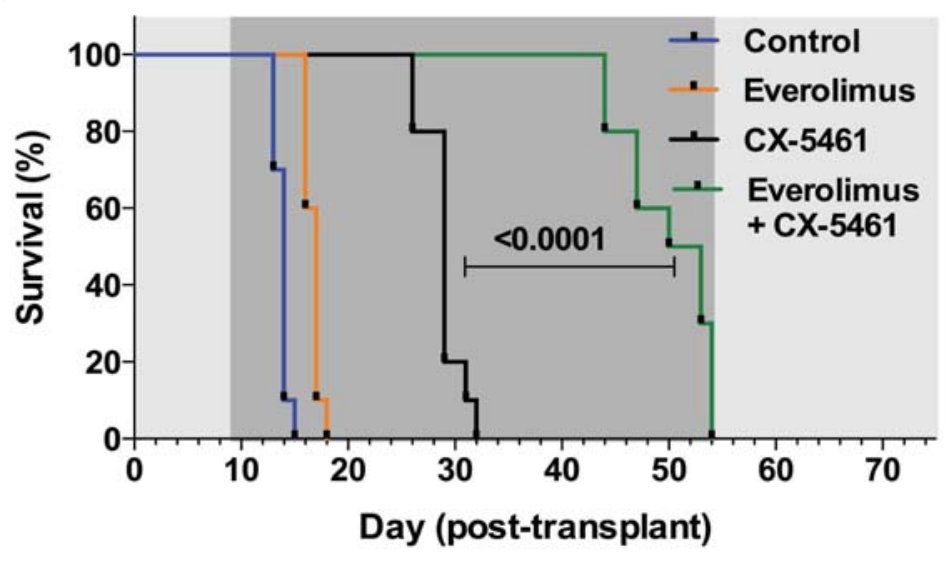

(D)

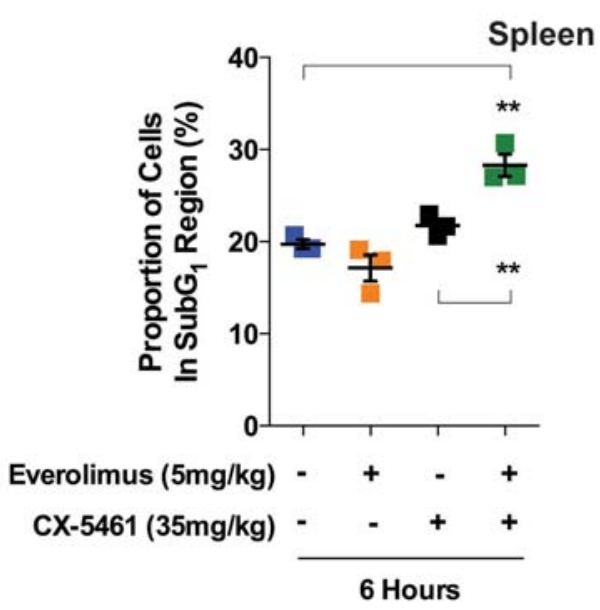

(F)

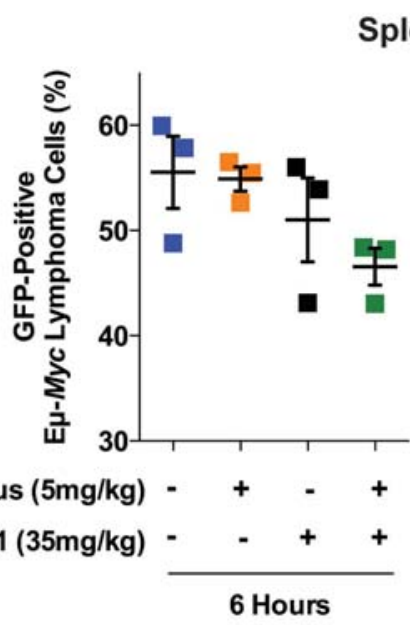

Everolimus (5mg/kg) - + - +

CX-5461 (35mg/kg) -

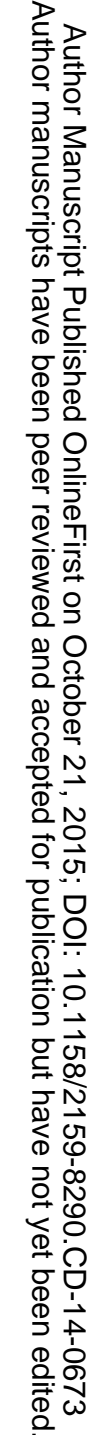


Figure Zuthor Manuscript Published OnlineFirst on October 21, 2015; DOI: 10.1158/2159-8290.CD-14-0673 Author manuscripts have been peer reviewed and accepted for publication but have not yet been edited.

(A)

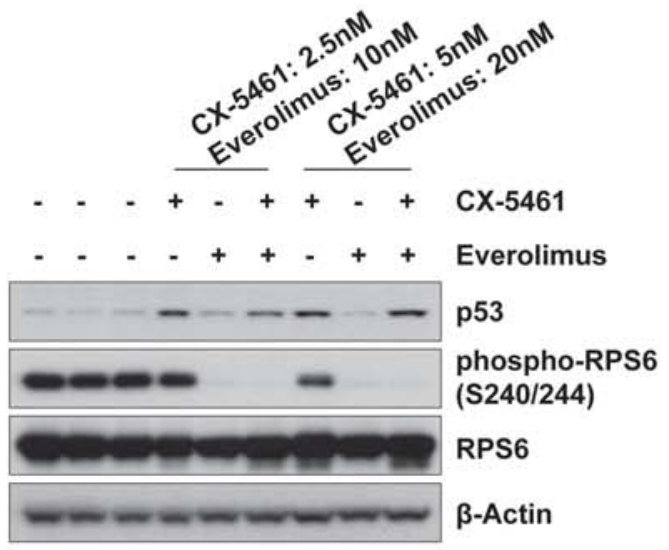

(C)

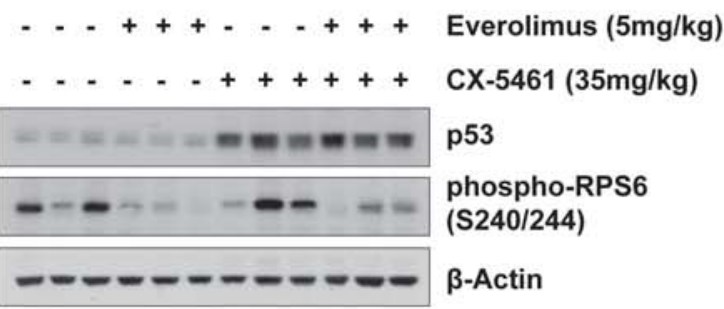

(E)

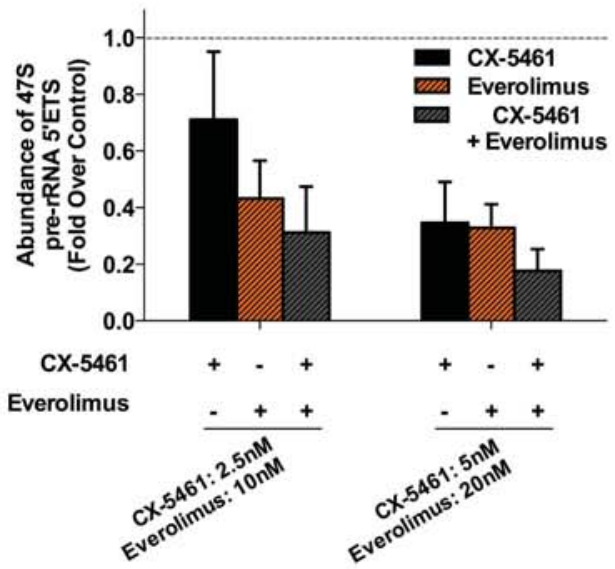

(G)

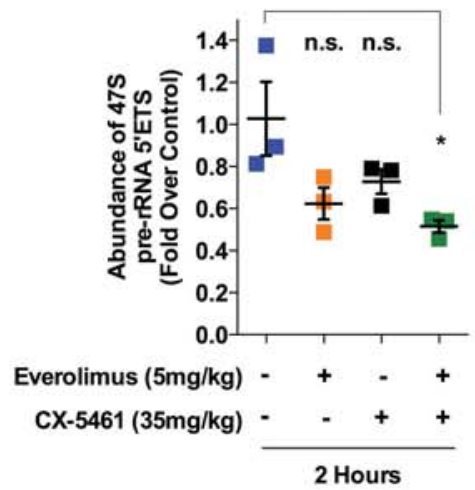

(B)

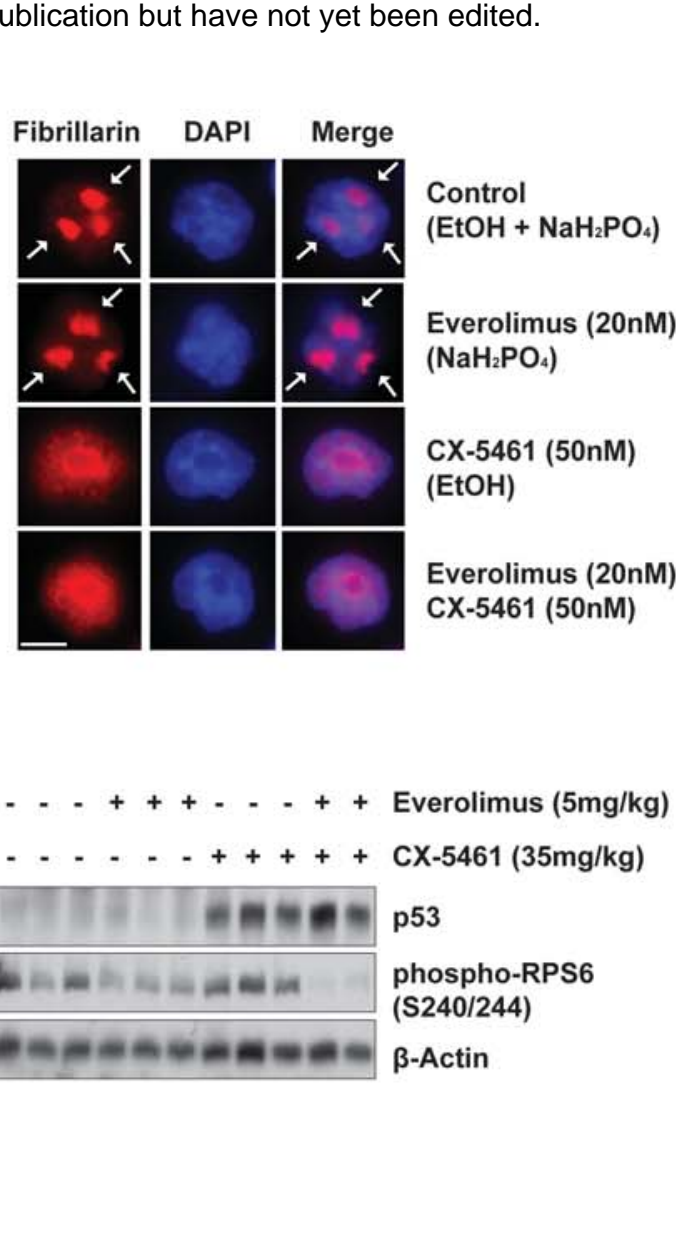

(D)

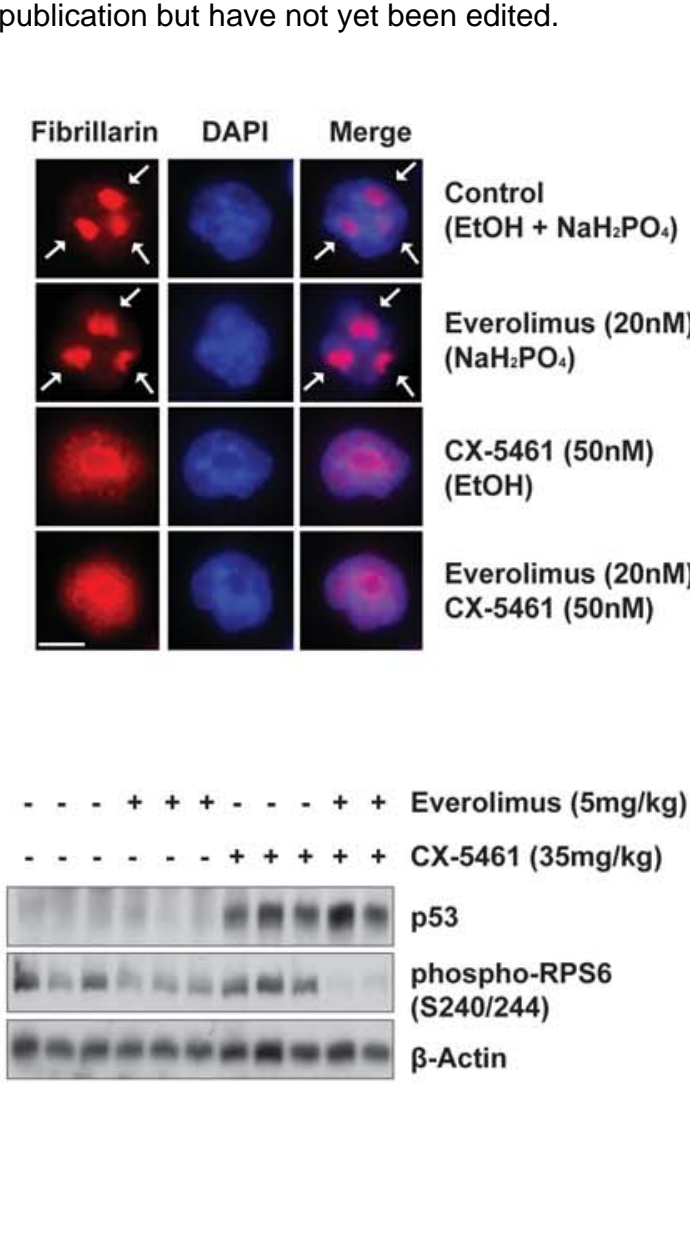

(F)

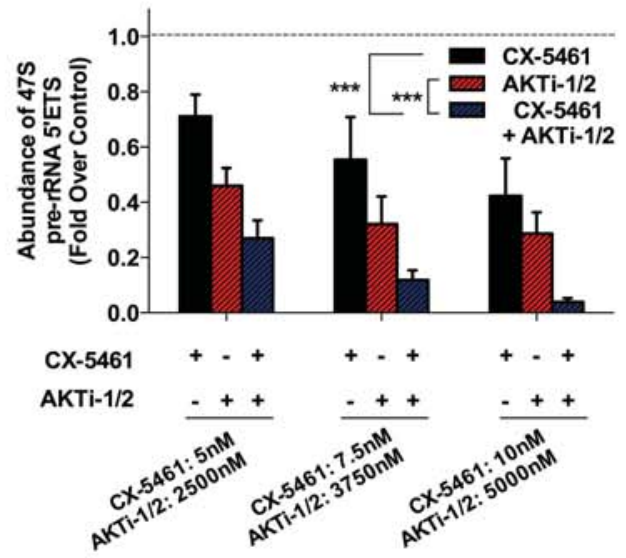

(H) 

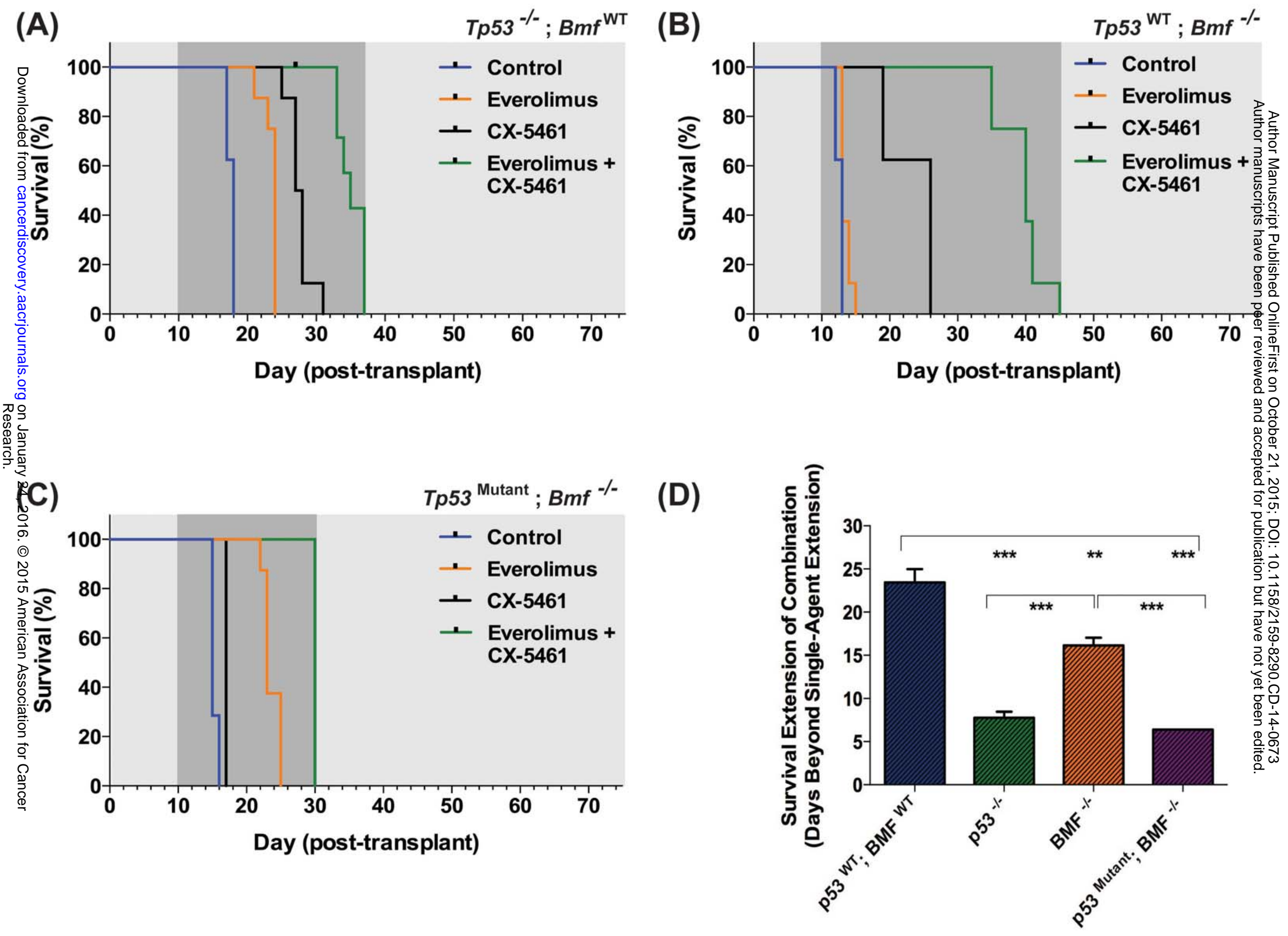


\section{CANCER DISCOVERY

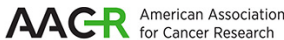

\section{Combination therapy targeting ribosome biogenesis and mRNA translation synergistically extends survival in MYC-driven lymphoma}

Jennifer R. Devlin, Katherine M. Hannan, Nadine Hein, et al.

Cancer Discov Published OnlineFirst October 21, 2015.

Updated version Access the most recent version of this article at: doi:10.1158/2159-8290.CD-14-0673

Supplementary Access the most recent supplemental material at:

Material http://cancerdiscovery.aacrjournals.org/content/suppl/2015/10/21/2159-8290.CD-14-0673.DC1.html

Author Author manuscripts have been peer reviewed and accepted for publication but have not yet been Manuscript edited.

\section{E-mail alerts Sign up to receive free email-alerts related to this article or journal.}

Reprints and To order reprints of this article or to subscribe to the journal, contact the AACR Publications Subscriptions Department at pubs@aacr.org.

Permissions To request permission to re-use all or part of this article, contact the AACR Publications Department at permissions@aacr.org. 